\title{
EDITORIAL
}

\section{Some reflections on how not to get bitten by a clinical guideline}

\section{Hart}

Heart 2002;87:501-502

\section{Clinical guidelines can operate legally as a sword, in that doctors can be criticised for not adhering to them, or as a shield to rebut criticism of inadequate treatment}

$\mathrm{T}$ he last few years have seen the rise of the clinical guideline, in particular those generated from central National Health Service (NHS) bodies such as the National Institute of Clinical Excellence (NICE). Some praise these nationwide emanations as promulgating the brave new world of robust evidence based medicine, others characterise (or caricature) them as dirigiste measures leading to "cookbook medicine" underscored by insidious rationing of the ingredients. This article, by a lawyer, does not seek to contribute to that debate. Its subject is very different. What legal effect do these guidelines have, as between doctor, patient and disciplinary body? More particularly, what is a clinician to do if he or she is seriously troubled about some specific recommendation in a guideline?

Clinical guidelines can operate legally in two principal ways, as a sword in that doctors can be criticised for not adhering to them, or as a shield in that doctors can rely upon them to rebut criticism of inadequate treatment. Though guidelines are plainly of considerable use in defending doctors*, I shall concentrate on their use as a sword, against doctors, because it raises far more difficult issues. Such issues can arise in either a claim by a disgruntled patient for clinical negligence or in disciplinary proceedings brought against the doctor before the General Medical Council (GMC).

\section{LEGAL PRINCIPLES}

Though there is no up-to-date case law on the effect of the NICE type guidance, the underlying legal principles are uncontroversial and can be shortly stated:

- A guideline, however august its provenance, has no automatic legal effect. It is not a tramline or a statute. It will probably contain some express caveat to the effect that, although doctors are expected to take it fully into account, it is not intended to override individual clinical judgment. Even if it does not

Correspondence to:

David Hart, Barrister,

1 Crown Office Row

Temple, London

EC4Y 7HH, UK:

david.hart@lcor.com

....................

*For example, Early v. Newham HA [1994] 5 Med LR 214; all Newham anaesthetists (including 7-8 consultants) decide on failed intubation drill; decision minuted; very difficult to criticise later adherence to the drill as negligent. contain such a caveat, it will almost certainly be interpreted in that way if it calls itself a guideline.

- Failing to comply with a guideline may be evidence of substandard or negligent care, but only if an independent medical expert advising the claimant characterises it having considered that individual claimant's case.

- Failing to comply with a guideline will not amount to negligent treatment if there is a responsible body of medical opinion which supports non-observance of the guideline. This is, of course, the well-known Bolam ${ }^{1}$ principle which governs all cases in which compensation claims are brought against the medical profession.

- The courts will, however, not simply accept the say-so of a defence expert; they must be satisfied that the opinion of that expert has a "logical basis", and that the expert has directed his mind to the "question of comparative risks and benefits" $\dagger$ of the impugned treatment or lack of it.

- Turning to disciplinary proceedings, an exercise of clinical judgment which is non-negligent in that it is defended by a responsible body of medical opinion is very unlikely to amount to "serious professional misconduct" before the GMC. ${ }^{2}$ A good illustration of this in a guidelines case is the decision of the Supreme Court of Western Australia in Cranley v. Medical Board of Western Australia. ${ }^{3}$ The doctor prescribed injectable diazepam to heroin addicts, in breach of the national methadone guidelines. His appeal against a finding of "infamous and improper conduct" was allowed, in the light of evidence that a respectable, if minority, opinion approved his management.

\section{EVIDENCE}

But it would be idle to pretend that all nonobservances of a guideline can be explained away without difficulty and without troubling one's defence union or claims handler. An example will demonstrate the point. The claimant injured by non-prescription of a drug points to a NICE guideline recommending its prescription. The guideline expressly incorporates reference to the evidence upon which it is based. The claimant finds an expert who confirms that there was no
†Quoted words from the more recent decision of the House of Lords in Bolitho v. City \& Hackney H.A. [1998] AC 232. 
contraindication specific to the claimant and goes on to state that it was substandard care not to prescribe the drug.

Thus far, the non-prescribing clinician is very much on the back foot. To respond, the clinician must obviously show that he or she was aware of the guideline and took a considered clinical judgment not to follow it. With a piece of mainstream nationwide guidance, awareness of the guidance may be easy to show. But upon what evidence was that clinical judgment based? Chat around the coffee machine? A medical meeting a little while ago, “but I can't remember the keynote speaker, and I am not sure whether it preceded or post-dated issue of the guideline"? A couple of instances recently where the clinician "thought" that the drug might have played some part in an adverse outcome?

Now the clinician may have plenty of things to say about the quality of the evidence supporting the recommendation in the guideline ("Grade C, and pretty ropey Grade $\mathrm{C}$ at that"), but such gripes may pale into significance when he analyses the status of his own (lack of) evidence, certainly if it goes no further than my almost certainly over-simplistic example above. All these problems will be compounded if the clinician under fire is not the consultant of 10 years standing but the junior doctor who did what he did because his consultant (now retired) told him to do it.

Now plainly there is no instant solution for the concerns expressed by individual clinicians about particular recommendations in a guideline which they feel are inadequately supported by the published evidence. Equally, they can take comfort from the fact every guideline contains in its caveatting clause an express injunction upon clinicians ultimately to follow their own clinical judgment. Put the other way around, to take account of guidance, does not mean slavishly to follow it. But there is a lot to be said for clinicians carrying out a pre-emptive mental review of the evidence which they would rely upon if their non-observance came to be challenged in the future. Put more concretely, "what paperwork could I produce for my lawyer if this decision or practice came under challenge? What information could my lawyer or defence union send to the GMC or claimant's lawyer, in order to ward off the threat of proceedings?"

The clinician's mental checklist might include answering the following questions. Was there published and cogently

$\ddagger$ The archiving pros and cons of the metre high column of paperwork in the corner of the consulting room or loft versus electronic storage will not be canvassed here, though the automatic dating of the latter might assist those seeking to prove when it was that the particular paper was received by the clinician.

$\S$ See the clinical meeting which assisted the hospital in Early, footnote ${ }^{\star}$ above. argued dissent at the time the recommendation went out to consultation? Has that dissent resurfaced in well regarded journals, and if not should it do so now? Does the clinician have a copy of any critical literature in his own personal archive? $\neq$ This last question is to counter any suggestion that the criticism of the recommendation is ex post facto rationalisation of a position not truly held by the clinician at the time. If there is nothing in the present or forthcoming literature, are there dated notes evidencing a region or hospital wide practice, its subscribers, and a summary of the reasons for the adoption of that practice?§ More apposite to junior clinicians, do individual clinical notes evidence knowledge of but considered divergence from the recommendation?

The upshot of the above is that clinicians unhappy with a recommendation in a guideline should consider creating a counter-guideline, albeit perhaps one of local effect, or at very least generating a paper trail, so as to evidence their reservations. That will enormously assist a rapid response to any letter of complaint, the rapidity being very important in seeing off the complaint before it becomes too established in the minds of the claimant and his lawyers.

I fear I must leave my readers to make their own assessment of the extent to which it is politically possible to take some or all those steps in the NHS of 2002, and also their likely efficacy in fending off managerial pressure to conform to nationwide guidance. One minor consolation, though, from the past. Though there have been veiled threats that NICE guidance may be enforced by some future strengthening of the powers available to NICE and the Commission for Health Improvement, ${ }^{4}$ even the most pessimistic of today's clinicians may think that they are unlikely to face the sanctions applicable to Egyptian military doctors who did not comply with their NICE predecessors-according to Diodorus Siculus, writing in the 2nd century BC:

"The physicians draw their support from the public funds and administer their treatment in accordance with a written law which was composed in ancient times by many famous physicians ... but if they go contrary to the law's prescriptions in any respect, they must submit to a trial with death as the penalty." ${ }^{\prime 5}$

\section{REFERENCES}

1 Bolam v. Friern Hospital Management Committee, [1957] 1 WLR 583

2 McCandless v. General Medical Council, [1996] 1 WLR 167: seriously negligent treatment required for serious profession misconduct. 3 [1992] 3 Med LR 94.

4 Department of Health. A first class service: quality in the new NHS. London: Department of Health, 1998.

5 O'Rourke AJ. In: Tingle J, Foster C, eds. Clinical guidelines: law, policy \& practice. London: Cavendish Publishing, 2002. This contains a good overview of the significance of clinical guidelines from the medical and legal perspective. 